\title{
Occurrence of Fumonisin B1 in Maize Kernels, Poultry and Livestock Feeds in Tamil Nadu, India
}

\author{
B. Jayarajavarma*, A. Kamalakannan and V. Paranidharan
}

Department of Plant Pathology, Centre for Plant Protection studies, Tamil Nadu Agricultural University, Coimbatore - 641003, Tamil Nadu, India

*Corresponding author

\section{A B S T R A C T}

\section{Keywords}

Mycotoxin, Fumonisin, HPLCELSD

Article Info

Accepted:

15 May 2019

Available Online:

10 June 2019
The level of mycotoxin fumonisin B1 in maize kernels, poultry and livestock feeds collected from various parts of Tamil Nadu, India has been analyzed using High performance Liquid Chromatographic coupled with evaporative light scattering detector (HPLC-ELSD). A total of 41 Maize samples (21 pre and Post-harvest maize kernels, 12 Poultry feeds and 8 livestock feeds) obtained from field, Poultry farm and retail shops. The results indicated that $71 \%$ maize kernels, $75 \%$ poultry feeds and $62 \%$ livestock feed samples contains FB1 with the levels ranged from 27.24 -118.21 ppm 31.56-93.75 ppm and 25.16-104.51ppm respectively. It indicated widespread prevalence of fumonisin B1 in maize, poultry and livestock feeds in different parts of Tamil Nadu, India.

\section{Introduction}

Fumonisins are Mycotoxins produced mainly by the fungus Fusarium verticillioides a primary fungal contaminant of Maize and maize based products throughout the world (Shephard et al., 1996). It was first discovered in South Africa in 1988 (Gelderblom et al., 1988; Marasas et al., 2001) FB1 is the most commonly found, not only in maize and maize-based foods, but also in beer, rice, sorghum, triticale, cowpea seeds, beans, soybeans and asparagus. FB1 can cause two diseases in farm animals. i.e leucoencephalomalacia and porcine pulmonary oedema in horses. It is also carcinogenic, hepatotoxic, nephrotoxic and embryotoxic in laboratory animals. In humans, fumonisins are associated with oesophageal cancer and neural tube defects based on studies conducted in Transkei and Texas (Marasas et al., 2001). The International Agency for Research on Cancer (IARC) designated FB1 in Group 2B as 'possibly carcinogenic to humans' (IARC 1993).Till now, twenty-eight types of fumonisins have been isolated and they can be classified into A, B, C and P series. FB1, FB2 and FB3 are the principal fumonisins analyzed as natural contaminants of cereals (Soriano et al., 2005; Wang et al., 2008). F. verticillioides produces several mycotoxins, 
the most prominent of which is called fumonisin B1 (FB1). The U.S. Food and Drug Administration guidelines for fumonisin in human foods and animal feeds is $4 \mu \mathrm{g} / \mathrm{g}$ and $<50 \mu \mathrm{g} / \mathrm{g}$ respectively.

Mycotoxin contamination in agricultural commodities has considerable economic implications. Losses from rejected shipments and lower prices for inferior quality can devastate the export markets of developing country. In India, more than one-quarter of tested maize samples exceeded the Indian tolerance limit of $30 \mathrm{ppb}$, and that if Codex standards were applied, nearly one-half (47 per cent) of the samples would have to be rejected from export (Van Egmond, 2002; Bhat et al., 2000) indicating high levels of contamination.

Several surveys have been conducted concerning the natural occurrence of fumonisin in corn samples collected from households in Linxian County. Chu and $\mathrm{Li}$ (1994) detected high level (18-155 ppm; mean, $74 \mathrm{ppm}$ ) and lower level (20-60 ppm; mean, $35.3 \mathrm{ppm}$ ) of fumonisin in household moldy samples. However, lower incidence and level of FB1 were also reported in other surveys conducted in Linxian County by (Yoshizawa et al., 1994) and (Wang and Zhu, 2002). The 91 percent maize samples contains the fumonisin level $0.1 \mathrm{ppm}$ to $87.0 \mathrm{ppm}$ and 84 percent of poultry feeds contain $0.1 \mathrm{ppm}$ to $87.0 \mathrm{ppm}$ level of fumonisin could be observed in Hariyana, India by N. Jindal et $a l .$, 1999). The high level FB1 (0.30-3.20 $\mu \mathrm{g} /$ $\mathrm{g}$; mean, $1.42 \mu \mathrm{g} / \mathrm{g}$ ) in samples from the granary, followed by household (0.25-1.80 ppm; mean, $0.73 \mathrm{ppm})$, central market (0.25$1.10 \mathrm{ppm}$; mean, $0.51 \mathrm{ppm})$, and store $(0.22$ $0.34 \mathrm{ppm}$; mean, $0.28 \mathrm{ppm}$ ) in china could be detected by (Wang. J. et al., 2008)

The aim of this study was to investigate the level of Fumonisin FB1 contamination in Pre and post-harvest maize kernels, Poultry feeds and livestock feed samples collected from different parts of Tamil Nadu, India using High performance Liquid Chromatographic coupled with evaporative light scattering detector (HPLC-ELSD)

\section{Materials and Methods}

\section{Survey and collection of samples}

A Surveys was conducted in different agroecological zones of Tamil Nadu, India and a total of 41 Maize samples (21 pre and Postharvest maize kernels, 12 Poultry feeds and 8 live stock feeds) obtained from field, Poultry farm and retail shops in order to understand the magnitude of fumonisin contamination in maize kernels, Poultry and livestock feeds.

\section{High performance Liquid Chromato- graphy (HPLC) analysis of Fumonisin (FB1)}

The HPLC system is an "Agilent 1200 series", consists of an isocratic unit with a quaternary pump capable of a flow rate of 0.2 - $10 \mathrm{ml} / \mathrm{min}$ and a suitable manual injector with Rheodyne 7725i 7-port sample injection valve capable of $10 \mu \mathrm{l}$ injections where the sample is loaded into the external $20 \mu \mathrm{l}$ sample loop through the injection port. A 15 $\mathrm{cm}$ long reversed-phase column containing C18 or C8 modified silica packing material of 3 to $5 \mu \mathrm{m}$ particle size is present inside the system for the separation of the compounds. The HPLC system is equipped with an evaporative light scattering detector.

The HPLC-ELSD method conditions were performed according to procedures with some modifications (Bojja et al., 2004). The mobile phases were (A) water- trifluoroacetic acid (TFA) (100:0.025, v/v) and (B) acetonitrileTFA (100:0.025, v/v), with a gradient of 0$20 \% \mathrm{~B}$ in $\mathrm{A}$ in the first $5 \mathrm{~min}, 20-40 \% \mathrm{~B}$ 
from 5 to $10 \mathrm{~min}, 40-80 \% \mathrm{~B}$ from 10 to 15 $\mathrm{min}, 80 \% \mathrm{~B}$ from 15 to $20 \mathrm{~min}$, and $80-0 \% \mathrm{~B}$ from 20 to $25 \mathrm{~min}$. The flow rate was 1.0 $\mathrm{ml} / \mathrm{min}$.

The conditions set for ELSD (Agilent 1260 infinity ELSD) were $45{ }^{\circ} \mathrm{C}$ of drift tube temperature, $2.0 \mathrm{l} / \mathrm{min}$ nitrogen gas flow and gain value of 1 in the impactor-on mode.

\section{Extraction and clean-up}

$10 \mathrm{~g}$ of fined maize samples were placed in a flask containing $25 \mathrm{ml}$ Acetonitrile/water $(1: 1, \mathrm{v} / \mathrm{v})$, then was placed in an orbital shaker overnight, and filtered with Whatman No. 1 paper under vacuum.

Ten milliliters filtrate was transferred into 50$\mathrm{ml}$ centrifugal tube and placed on the ice for $15 \mathrm{~min}$. and centrifuged at $7000 \mathrm{rpm}$ for 10 min at $4^{\circ} \mathrm{C}$, then transferred to a new $50-\mathrm{ml}$ centrifugal tube containing $300 \mathrm{mg}$ Amberlite XAD-4 (37380-42-0, Sigma-Aldrich Co., USA) which had been activated with $2 \mathrm{ml}$ methanol and washed with deionized water, and the tube was stirred for $5 \mathrm{~h}$ or overnight in an orbital shaker after adding $40 \mathrm{ml}$ deionized water. The XAD-4 beads were then washed with $200 \mathrm{ml}$ deionized water, then transferred the XAD-4 beads to a Bond Elute column without stuffing by deionized water and the toxins were eluted with $3 \mathrm{ml} 100 \%$ methanol. The eluent was dried under vacuum with freezing at $65^{\circ} \mathrm{C}$ and dissolved in $200 \mu \mathrm{l}$ deionized water. The solution was filtered through a $0.2 \mu \mathrm{m}$ syringe-filter and $20 \mu \mathrm{l}$ was injected directly into the HPLC-ELSD. All samples were analyzed in triplicate.

\section{Preparation of standards}

Fumonisin standards: Fumonisin standards were prepared in acetonitrile: water (1:1) and stored at $4^{\circ} \mathrm{C}$. Standards stored for long periods in methanol undergo slow degradation. Stock solution of individual fumonisin standards of concentration 250 $\mu \mathrm{g} / \mathrm{ml}$ were used, from which a working standard was prepared with a concentration of $10 \mu \mathrm{g} / \mu \mathrm{l}$ and diluted into four different concentration $0.15,0.3,0.6,1.2 \mu \mathrm{g} / \mu \mathrm{l}$. The calibrant stock solutions of individual FB1 acetonitrile-water $(50+50, \mathrm{v} / \mathrm{v})$ was prepared. Fumonisin calibrant solutions are stable for 6 months when stored at $4{ }^{\circ} \mathrm{C}$. A calibration curve was prepared from the four different dilutions of $0.15,0.3,0.6,1.2 \mu \mathrm{g} / \mu \mathrm{l}$ concentration of $10 \mu \mathrm{g} / \mu \mathrm{l} .20 \mu \mathrm{l}$ of dilution was directly injected to the HPLC system. Calibration plot was prepared and checked for linearity.

\section{Determination}

The established condition standard FB1 gave a peak at a retention time of $11.33 \mathrm{~min}$. The peak areas for fumonisin in the sample chromatogram are determined and the amount of each fumonisin analogue injected is determined from the calibration plot. From the calibration curve the amount of Fumonisin level in nanogram in the aliquot of solution injected into the HPLC was read from the calibration curve.

\section{Results and Discussion}

In the present study 41 samples consisting of pre and post-harvest maize kernels, poultry and livestock feeds collected from farmer's fields, poultry farms and retail shops were analyzed for $\mathrm{FB}_{1}$ contamination. As shown in Table 1, Fumonisin contamination in maize kernels and feeds was observed in more than 70 per cent of the samples tested. The pre harvest maize samples were contaminated with $\mathrm{FB}_{1}$ at level ranging from 27.24 to 113.9 ppm. Most of the post-harvest maize kernels samples were contaminated with $\mathrm{FB}_{1}$ at level ranging from 38.16 to $118.21 \mathrm{ppm}$. five samples contained $\mathrm{FB}_{1}$ above $100 \mathrm{ppm}$. 
Table.1 Fumonisin (FB1) contamination in maize kernels, poultry and livestock feed samples in Tamil Nadu, India

\begin{tabular}{|c|c|c|c|c|}
\hline Sample ID & Place & District & Sample & FB1 (ppm) \\
\hline S1 & TNAU & Coimbatore & Poultry feed & 37.09 \\
\hline S2 & Kuppanur & Coimbatore & Post-H & 0 \\
\hline S3 & Devarayapuram & Coimbatore & Pre-H & 113.9 \\
\hline S4 & Irugur & Coimbatore & Post-H & 41.42 \\
\hline S5 & Karamadai & Coimbatore & Poultry feed & 0 \\
\hline S6 & Annur & Coimbatore & Live stock & 69.42 \\
\hline S7 & Ukkadam & Coimbatore & Post-H & 0 \\
\hline S8 & Thethipalayam & Coimbatore & Post-H & 38.16 \\
\hline S9 & Sulur & Coimbatore & Pre-H & 27.24 \\
\hline S10 & Udumalpet & Coimbatore & Poultry feed & 44.72 \\
\hline S11 & Uthukuli & Coimbatore & Pre-H & 34.26 \\
\hline S12 & Pollachi & Coimbatore & Poultry & 31.56 \\
\hline S13 & Palladam & Thirupur & Live stock & 0 \\
\hline S14 & Senjerimalai & Thirupur & Live stock & 25.16 \\
\hline S15 & Gopichettipalayam & Erode & Post-H & 0 \\
\hline S16 & Moolanur & Erode & Poultry feed & 0 \\
\hline S17 & Bhavanisagar & Erode & Post-H & 42.06 \\
\hline S18 & Ammapetai & Erode & Post-H & 58.19 \\
\hline S19 & Sathyamangalam & Erode & Live stock & 0 \\
\hline $\mathbf{S 2 0}$ & Attur & Salem & Poultry & 72.07 \\
\hline S21 & Kandampalayam & Namakkal & Post-H & 0 \\
\hline S22 & Rasipuram & Namakkal & Pre-H & 76.24 \\
\hline $\mathbf{S 2 3}$ & Thiruchenkode & Namakkal & Poultry feed & 73.3 \\
\hline S24 & Paramathi & Namakkal & Live stock & 41.91 \\
\hline S25 & Vagarai & Ariyalur & Post-H & 67.42 \\
\hline S26 & Thuraiyur & Ariyalur & Pre-H & 0 \\
\hline S27 & Jeyankondam & Ariyalur & Poultry feed & 89.36 \\
\hline S28 & Padalur & Perambalur & Post-H & 82.97 \\
\hline S29 & Thuraimangalam & Perambalur & Live stock & 78.54 \\
\hline S30 & Karai & Perambalur & Pre-H & 0 \\
\hline S31 & Ammapalayam & Perambalur & Post-H & 114.4 \\
\hline S32 & Alanthur & Perambalur & Poultry feed & 75.81 \\
\hline S33 & Siruganur & Trichy & Live stock & 0 \\
\hline S34 & Srirangam & Trichy & Pre-H & 71.08 \\
\hline S35 & Andipatti & Madurai & Poultry feed & 0 \\
\hline S36 & Madurai & Madurai & Post-H & 118.21 \\
\hline S37 & Srivilliputhur & Viruthunagar & Poultry & 93.75 \\
\hline S38 & Rajapalayam & Viruthunagar & Live stock & 104.51 \\
\hline S39 & Mamsapuiram & Viruthunagar & Poultry feed & 70.48 \\
\hline S40 & Devathanam & Viruthunagar & Pre-H & 107.6 \\
\hline S41 & Ottachanthiram & Dindugal & Post-H & 72.58 \\
\hline
\end{tabular}

Pre-H: Pre harvest maize kernels. Post-H: Post harvest maize kernels 
In poultry feeds, $\mathrm{FB}_{1}$ was detected in 9 out of 12 samples and the levels ranged from 31.56 to $93.75 \mathrm{ppm}$. Among the 8 livestock feed samples evaluated, 5 samples were contaminated with $\mathrm{FB}_{1}$ at level ranging from 25.16 to $104.51 \mathrm{ppm}$. Among all the samples, the highest level $118.21 \mathrm{ppm}$ of $\mathrm{FB}_{1}$ was observed in the post-harvest maize kernel obtained from the Madurai district. The high level of Fumonisin in maize kernels and feeds present a risk for human and animal consumption. The occurrence of high levels of $\mathrm{FB}_{1}$ in food and feed stuffs has been reported by several workers (Chu and $\mathrm{Li}$, 1994; Yoshzawa et al., 1994; Jindal et al., 1999, Wang and Zhu, 2002). Chu and Li 1994 reported that $\mathrm{FB}_{1}$ content was high with an average level of 19-107.5 (mean 54.65) ppm in maize samples collected from households of Linxian country. However the lower incidence and level of $0.872 \mathrm{ppm}$ were found in the house hold maize samples (Yoshzawa et al., 1994). The work done by Wang and Zhu (2002) reported that FB1at the concentrations ranged from 1.07 to $2.56 \mathrm{ppm}$ was detected in 50\% moldy corns obtained from maize field (Jindal et al., 1999) analyzed a total of 100 maize and 50 poultry feed samples collected from nine and eight districts of Haryana and reported that $91 \%$ of maize samples, $84 \%$ of poultry feed samples contain a fumonisin levels of $0.1-87.0 \mathrm{ppm}$ and 0.02-28.0 ppm respectively (Wang et al., 2008) analyzed a total of 104 corn kernel samples obtained from local households, granaries, wholesale markets (central markets), and retail markets (stores and supermarkets) and reported that the Fumonisin B1 (FB1) concentration was found with a positive rate of $61.5 \%, 50 \%, 33.3 \%$, and $17 \%$, respectively. No fumonisin was detected in samples from the supermarket. The highest FB1 levels (0.30-3.20 ppm; mean, $1.42 \mathrm{ppm}$ ) were found in samples from the granary, followed by household $(0.25$ $1.80 \mathrm{ppm}$; mean, $0.73 \mathrm{ppm})$, central market
(0.25-1.10 ppm; mean, $0.51 \mathrm{ppm})$, and store (0.22-0.34 ppm; mean, $0.28 \mathrm{ppm})$. The author concluded that the variation of FB1 content among different surveys in corn from households in Linxian County may be related to rainy during and after harvest as well as the improper storage and humidity. It was also reported that the toxins could be formed during post-harvest storage, especially when corn was inadequately stored at high temperature and high relative moisture (Jackson and Jalonski, 2004). It is well known that production of Fumonisin in maize is dependent upon a number of factors such as temperature, humidity, insect injury, handling during harvesting and storage (Wang et al., 2008). The level of $\mathrm{FB}_{1}$ in more than $70 \%$ of the contaminated pre- and post-harvest maize kernel samples exceeded the tolerance level fixed by the World Health Organization. Hence, regular monitoring of the level of fumonisin in maize and its feeds is very important to ensure the safety and quality of maize and its poultry, animal feeds. In the present study the fumonisin concentration in general are exceeded the admissible limits. Inappropriate storage conditions and field contamination of grains could be implicated the fumonisin production.

\section{References}

Bhat, R.V., Shetty, H.P.K. and Vasanthi, S. 2000. Human and animal health significance of mycotoxins in sorghum with special reference to fumonisins. In: Technical and Institutional Options for sorghum grain mould management. Proceedings of an international consultation, 2000 May 18-19. ICRISAT. Patancheru: India, pp. 107.

Bojja, R. S., Cerny, R. L., Proctor, R. H., and Du, L. C. 2004. Determining the biosynthetic sequence in the early steps of the fumonisin pathway by use of three gene-disruption mutants of 
Fusarium verticillioides. Joul. of Agrl and Food Chem., (52) 2855-2860.

Chu, F.S., and Li, G.Y. 1994. Simultaneous occurrence of fumonisin B1 and other mycotoxins in moldy corn collected from the People's Republic of China in regions with high incidences of esophageal cancer. Applied and Environmental Microbiology, 60, 847852.

Gelderblom, W. C. A., Jaskiewicz, K., Marasas, W. F. O., Thiel, P. G., Horak, R. M., Vleggaar, R. and Kriek, N. P. J. 1988. Fumonisins: novel mycotoxins with cancer-promoting activity produced by Fusarium moniliforme. Appl. Environ. Microbiol., 54: 18061811.

IARC (International Agency for Research on Cancer 1993. Monographs on the Evaluation of Carcinogenic Risks to Humans No.56. Lyon (France): IARC Press: pp.489-521.

Jindal N., S.K. Mahipal and G.E. Rottinghaus, 1999. Occurrence of fumonisin B1 in maize and poultry feeds in Haryana, India Mycopathologia 148: 37-40,

Marasas, W.F.O., Miller, J.D., Riley, R.T. and Visconti, A. 2001. Fumonisins occurrence, toxicology, metabolism and risk assessment. In: Summerell, B.A., Leslie, J.F., Backhouse, D., Bryden, W.L., Burgess, L.W. (Eds.), Fusarium, Paul E. Nelson Memorial Symposium. APS Press, St. Paul, MN. pp. 332-359.

Shephard G.S., Thiel, P.G., Stockenstrom,
S.and Sydenham, E.W. 1996. Worldwide survey of fumonisin contamination of corn and corn-based products. J AOAC Int., 79:671-687.

Soriano, J.M., Gonzalez, L. and Catala, A.I. 2005. Mechanism of action of splingolipids and their metabolites in the toxicity of fumonisin B1. Prog. Lipid Res. 44: 345-356.

Van Egmond, H. P. 2002. Worldwide regulations for mycotoxins. Adv. Exp. Med. Biol. 504: 257-269.

Wang, J., Y.Zhou, Qiaomei Wang 2008: Analysis of mycotoxin fumonisisn in corn products high performance liquid chromarography coupled with evaporative light scattering detection, Food Chemistry (107) 970-976

Wang, J., Zhou, Y., Liu, W., Zhu, X., Du, L. and Wang, Q. 2008. Fumonisin level in corn-based food and feed from Linxian Country, a high-risk area for esophageal cancer in China. Food Chem. 106: 241246.

Wang, Y. and Zhu, T. X. 2002. Determination of FB1 in corn with high incidence of esophageal cancer in Linxian Jingtoucun. J. Chi. Agrl. Un., 7(1): 9-13 (in Chinese).

Yoshizawa, T., Yamashita, A., and Luo, Y. 1994. Fumonisin occurrence in corn from high- and low-risk areas for human esophageal cancer in China. Appl. Environ. Microbiol., 60: 16261629.

\section{How to cite this article:}

Jayarajavarma, B., A. Kamalakannan and Paranidharan, V. 2019. Occurrence of Fumonisin B1 in Maize Kernels, Poultry and Livestock Feeds in Tamil Nadu, India. Int.J.Curr.Microbiol.App.Sci. 8(06): 1792-1797. doi: https://doi.org/10.20546/ijcmas.2019.806.214 